\title{
Analysis of SSI Effect on Damping Effect of Mild Steel Damper
}

\section{Peizhen LI}

State Key Laboratory of Disaster Reduction in Civil Engineering,

Tongji University

Shanghai, China

e-mail: lipeizh@tongji.edu.cn

\author{
Hao LI \\ State Key Laboratory of Disaster Reduction in Civil \\ Engineering, \\ Tongji University \\ Shanghai, China \\ e-mail: lihaocqu@163.com
}

\begin{abstract}
The thesis takes a ten-story frame structure with three span as research object to study the effect of SoilStructure Interaction (SSI) on the damping effect of mild steel damper. The equivalent linearization model is adopted as the constitutive model of soil. A material damping input method available in ANS YS was adopted to account for the difference of the soil damping ratio and that of the concrete superstructure in SSI systems. Shanghai bedrock waves were selected as the input earthquake, called SHW1 wave and SHW2 wave. The results indicate that the mild steel damper has relatively good damping effect on frame structure under rigid foundation assumption or considering SS I effect and it can control displacement response, inter-story shear force and other indexes of structure well. The damping rate considering SS I effect decreases in some degree, which indicates that SSI effect will reduce the damping effect of mild steel damper on frame structure, thus under rigid foundation assumption, the design of damping structure's mild steel damper will be unsafe in engineering application.
\end{abstract}

Keywords-soil-structure interaction; mild steel damper; aseismic design; damping effect

\section{INTRODUCTION}

In recent years, structural vibration control technology has been widely used to reduce the dynamic response of the structure under earthquake [1,2]. Scholars at home and abroad has put forward many control methods, among which seismic energy dissipation is a kind of passive control method, which can transfer the seismic energy inputted into structure to dedicated members and then absorb and dis sipate the energy so as to ensure the safety and reliability of main structure. Among various devices for seismic energy dissipation, mild steel damper is widely applied in engineering circle for its good workability, stable hysteretic behavior, low construction cost and maintenance expense, good replaceability and other advantages.

At present, many researches have paid attention to SSI effect's impact on structural dynamic effect [3]; and many new analysis methods, such as Pushover is introduced [4]; and scholars start to study the applications in seismic is olation and other new systems [5]. However, the researches on damper's damping effect in system considering SSI effect are deficient at present. Thus the study on the effect of SSI on mild steel damper's damping effect has good guiding significance to actual engineering application and can also enrich research results in the relevant fields.

\section{MODEL BULDING AND PARAMETER SELECTION}

\section{A. Main Structure Building}

The structure model has totally 10 stories. The story height is $3.6 \mathrm{~m}$. The thickness of slab is $120 \mathrm{~mm}$. The dimension of column section is $550 \mathrm{~mm} \times 550 \mathrm{~mm}$ and the dimension of beam section is $300 \mathrm{~mm} \times 500 \mathrm{~mm}$. The strength grade of concrete is $\mathrm{C} 35$. The dead load of typical floor is uniform load of $5.0 \mathrm{kN} / \mathrm{m}^{2}$ and the live load is $2.0 \mathrm{kN} / \mathrm{m}^{2}$. The foundation form is pile raft foundation. The thickness of raft board is $1000 \mathrm{~mm}$. The top elevation of raft board is \pm $0.000 \mathrm{~m}$. The pile form is square pile with section dimension of $450 \mathrm{~mm} \times 450 \mathrm{~mm}$, and the pile is $38 \mathrm{~m}$ long.

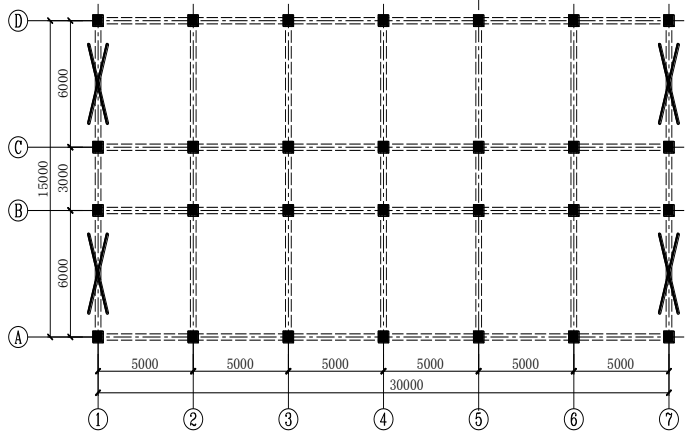

Figure 1. Floor plan of typical floor structure

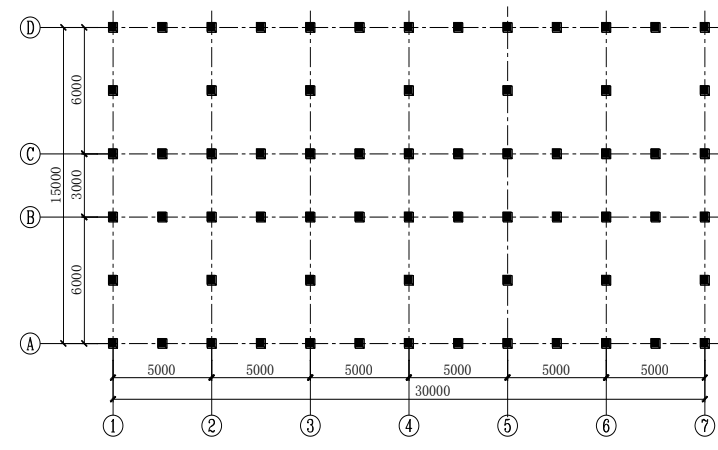

Figure 2. Pile foundation layout 
TABLE I. PERFormance PARAMETER OFMILD SteEl DAMPER

\begin{tabular}{|c|c|c|c|}
\hline Initial Stiffness (kN/m) & Yield Displacement (mm) & Yield Stiffness Ratio & Yield Load (kN) \\
\hline 100000 & 2 & 0.05 & 200 \\
\hline
\end{tabular}

TABLE II. PHYSICAL AND MECHANICAL PARAMETERS OF SOIL MASS

\begin{tabular}{|c|c|c|c|c|c|c|c|}
\hline $\begin{array}{l}\text { Layer } \\
\text { No. }\end{array}$ & $\begin{array}{c}\text { Name of Soil } \\
\text { Layer }\end{array}$ & $\begin{array}{l}\text { Buried Depth of } \\
\text { Bedding (m) }\end{array}$ & $\begin{array}{c}\text { Den sity } \rho \\
\left(\mathrm{t} / \mathbf{m}^{3}\right)\end{array}$ & $\begin{array}{c}\text { Poisson's } \\
\text { Ratio } \\
\gamma\end{array}$ & $\begin{array}{l}\text { Shear } \\
\text { Velocity } \\
\mathbf{v}_{\mathbf{s}}(\mathbf{m} / \mathbf{s})\end{array}$ & $\begin{array}{c}\text { Dynamic } \\
\text { Shear } \\
\text { Modulus } \\
G_{d}(\mathrm{MPa})\end{array}$ & $\begin{array}{c}\text { Dynamic Elasticity } \\
\text { Modulus } \\
\mathbf{E}_{d}(\mathbf{M P a})\end{array}$ \\
\hline (1) & plain fill & 2.2 & - & - & 107 & $\begin{array}{l}- \\
\end{array}$ & - \\
\hline (2) & silty clay & 3.8 & 1.86 & 0.3 & 125 & 29.1 & 75.6 \\
\hline (3) & mucky silty clay & 10.3 & 1.76 & 0.35 & 111 & 21.7 & 58.5 \\
\hline (4) & mucky clay & 19.4 & 1.68 & 0.42 & 161 & 43.5 & 123.7 \\
\hline (5) & clay & 25.9 & 1.74 & 0.42 & 214 & 79.7 & 226.3 \\
\hline (6) & silty clay & 29 & 1.96 & 0.25 & 226 & 100.1 & 250.3 \\
\hline (7) $1 \mathrm{a}$ & sandy silt & 36.3 & 1.88 & 0.3 & 193 & 70.0 & 182.1 \\
\hline (7) $1 b$ & silt & 58.9 & 1.89 & 0.3 & 274 & 141.9 & 368.9 \\
\hline$(8) 1$ & silty clay & 61.2 & 1.94 & 0.3 & 268 & 139.3 & 362.3 \\
\hline (8) 2 & $\begin{array}{l}\text { silty clay and } \\
\text { clayed silt } \\
\text { interbedding }\end{array}$ & 66.7 & 1.9 & 0.3 & 322 & 197.0 & 512.2 \\
\hline (9) & silt & $>66.7$ & 1.9 & 0.3 & 298 & 168.7 & 438.7 \\
\hline
\end{tabular}

Four mild steel dampers are placed symmetrically in each story to avoid torsion effect occurring in structure. The layout of mild steel dampers is shown in the Figure 1 and the performance parameters are shown in the Table 1. In Ansys, Co mbin 40 ele ment is adopted to simulate mild steel dampers [6].

The ground adopts soft soil of some geological survey report, the parameters of soil layers are shown in the table 2 , calculated depth is assumed to be $70 \mathrm{~m}$. The distribution of soil layers is (from top to bottom): (1) plain fill, (2) silty clay, (3) mucky silty clay, (4) mucky clay, (5) clay, (6) silty clay, (7) 1a sandy silt, (7) 1b silt, (8) 1 silty clay, (8) 2 silty clay and clayed silt interbedding, (9) silt. According to relevant stipulations of Code for Seis mic Design of Buildings [7], the ground is IV class ground. The seismic fortification intensity of this project is 8 degree. The designed basic seismic acceleration value is $0.2 \mathrm{~g}$ and designed seismic group is group 1.

\section{B. Selection of Damping Ratio Model}

During calculation, structure's damping ratio is assumed to be $5 \%$, the damping ratio of soil is assumed to be the damping ratio obtained through iteration of equivalent linearization model. In terms of the issue that different materials have different damping ratios, the damping ratio of each material shall be inputted respectively in the calculation and damping matrix shall be formed according to directly integrating method [8]. It is very convenient to input different damping ratios as per different materials by using the input method of material's damping ratio provided in ANS YS program.

\section{Constitutive Model of Soil}

The equivalent linearization model is adopted as the constitutive soil [9]. This thesis adopts soil skeleton curve of Davidenkov model [10], the relation of modulus ratio is shown in formula (1):

$$
\frac{G}{G_{\max }}=1-H(\gamma)
$$

Among which,

$$
H(\gamma)=\left[\frac{\left(|\gamma| / \gamma_{r}\right)^{2 B}}{1+\left(|\gamma| / \gamma_{r}\right)^{2 B}}\right]^{A}
$$

For the relation $D / D_{\max }$, it can be indicated by following empirical formu la according to relevant test results:

$$
\frac{D}{D_{\max }}=\left(1-\frac{G}{G_{\max }}\right)^{\beta}
$$

In the formula: $G_{\max }$ and $D_{\max }$ are respectively the maximum dynamic shear modulus and the maximum damping ratio, which can be determined through test or empirical formula; $\gamma=\tau_{\max } / G$ is the referential shear strain amplitude value. $\tau_{\max }$ is the limit value with soil's shear strength as asymptotic line when $\gamma$ is large enough and it is called final stress amplitude value. $\beta$ is shape coefficient of $D / D_{\max } \sim \gamma$ curve, for most soils, the value of $\beta$ is between $0.2 \sim 1.2$, and it can be 1.0 for soft soil. 


\section{Implementation of Soil Artificial Boundary}

The viscoelasticity artificial boundary is adopted as local artificial boundary. The longitudinal dimension of the soil is taken as quintuple structural dimension and the lateral dimension of the soil is taken as twentyfold structural dimension [11]. The recommended value in literature [12] is taken as correction coefficient of boundary parameter. When implementing viscoelasticity artificial boundary in ANSYS program, one-dimensional spring-damper elements Combin 14 are added in three directions of soil boundary nodes and the spring stiffness and damping coefficient of each element need multiplying by dominant area of nodes where the ele ment locates.

\section{E. Selection of Seismic Wave}

$\mathrm{X}$-direction time courses of the first two seismic ground motion acceleration time courses (i.e. SHW1 wave and SHW2 wave) given in Shanghai Code of Aseismic Design of Buildings are selected for the seismic wave inputted in model [13]. According to relevant principles of seismic wave truncation, this thesis takes the first 36s and 30s of SHW1 wave and SHW2 wave respectively for calculation. The time intervals of two waves are $0.02 \mathrm{~s}$.

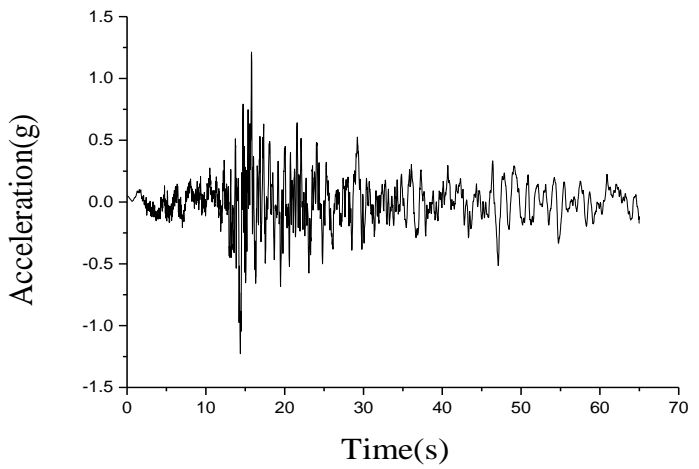

(a) SHW1 ground wave

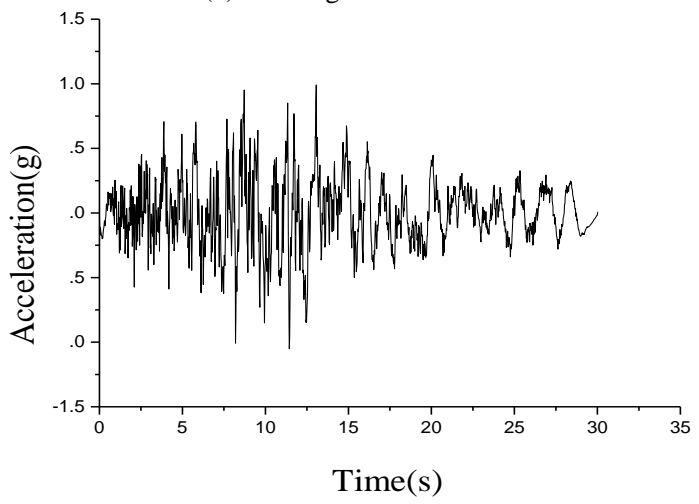

(b) SHW2 ground wave

Figure 3. Time course of SHW1 and SHW2 wave

\section{MODEL CALCULATIONS AND ANALYSIS}

\section{A. Structural Displacement of Total Floor Area}

Under rigid foundation assumption, the structural deformation of frame structure and damping structure under the two seis mic waves are all shear-type, which indicates that the setting of mild steel damper hasn't changed the deformation shape of structure. On the other hand, structure's lateral resisting stiffness will increase due to the stiffness added on structure by mild steel damper, thus mild steel damper has prominent effect on controlling displacement.

After considering SSI effect system, the shape of displacement peak value at bottom of structure's displacement curve is flexural, and the displacement peak curve of upper structure is shear-type. In general, the peak curve of the structural displacement is shear-flexural type curve, whose shape becomes more flexu ral obviously after adding mild steel damper. Meanwhile, it can be seen that the displacement of structure's lower floors has no obvious change after installing mild steel damper and the displacement difference is either positive or negative while the displacement of structure's upper floors decreases obviously. The above changes are due to the stiffness added on structure by mild steel damper.

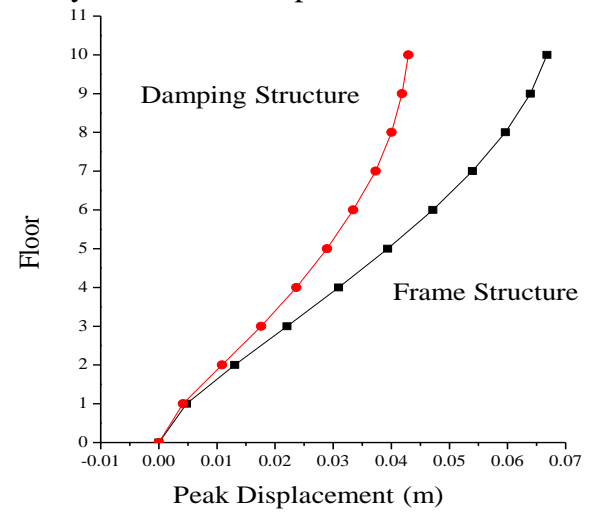

(a) SHW 1 ground wave

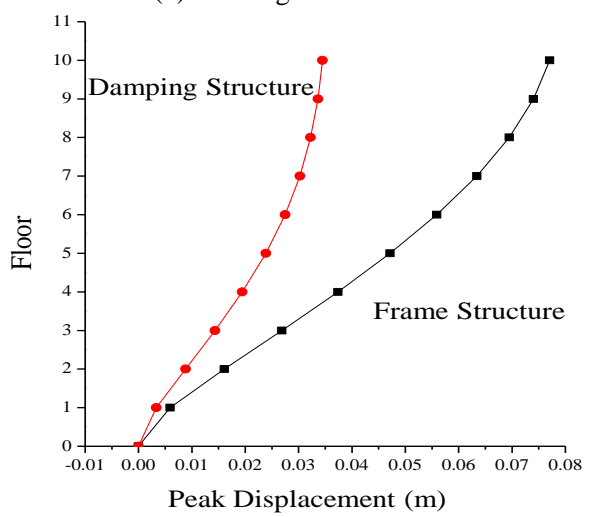

(b) SHW2 ground wave

Figure 4. Displacement peak curve of structure floor under rigid foundation assumption 


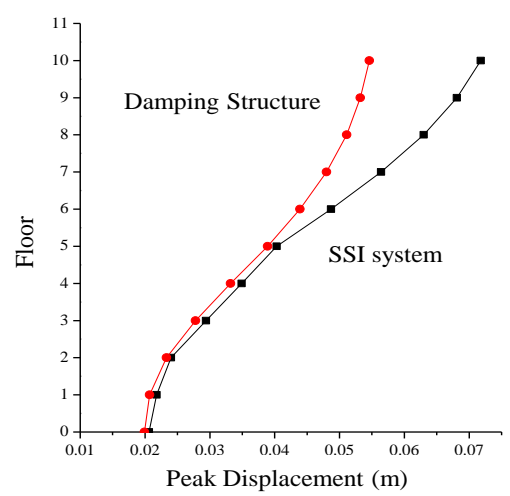

(a) SHW1 ground wave

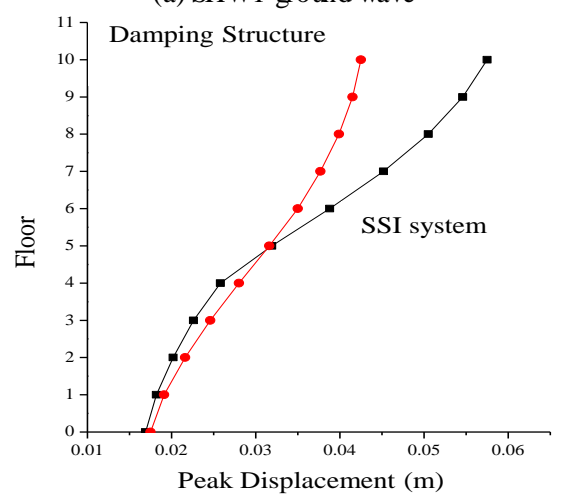

(b) SHW2 Ground Wave

Figure 5. Displacement peak curve of total floor area considering SSI effect

\section{B. Structural Story Drift Response}

Under rigid foundation assumption, the maximum story drift angles of frame structure and damping structure are all on the third floor. In addition, it can be found that damping rate of damping structure will increase with the increase of floors. It is because that although the performance parameters of mild steel dampers installed on each floor are the same, the seismic forces each floor bears are different.

Under the effect of SHW1, the maximum story drift angles of SSI system and its damping structure are all on the third floor. Under the effect of SHW2, the maximum story drift angles of SSI system and its damping structure are on the fifth floor and the third floor respectively. The story drift angles under the two seismic waves are different in a large degree, which indicates that the type of seismic wave has great influence on story drift angle of structure. In spite of different seismic waves, the damping rate of mild steel damper will increase with the increase of floors.

Generally, it can be found in Figure 7 that the damping effect of mild steel damper on story drift is obvious, especially on upper floors of structure. While the damping effect of mild steel damper on lower two layers of structure is not obvious.

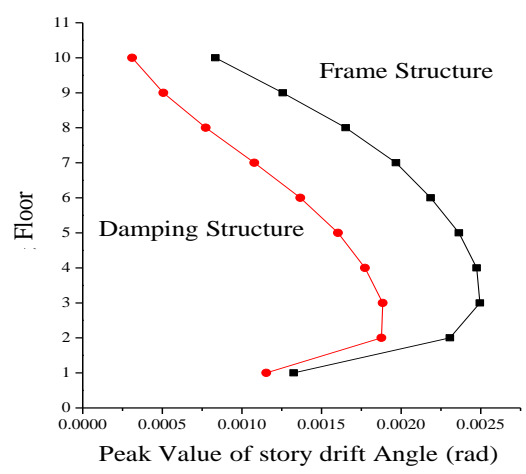

(a) SHW1 ground wave

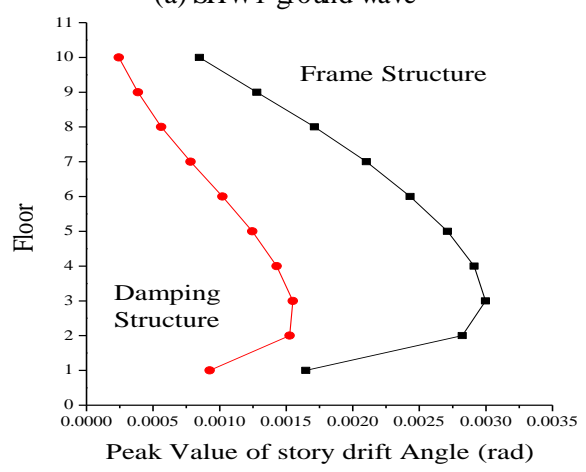

(b) SHW2 ground wave

Figure 6. Story drift angle peak curve of structure under rigid foundation assumption

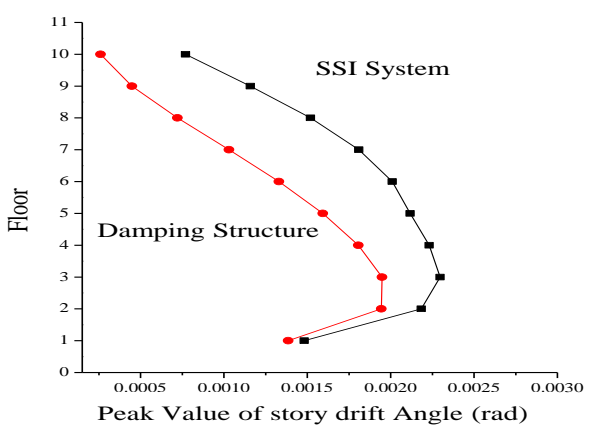

(a) SHW1 ground wave

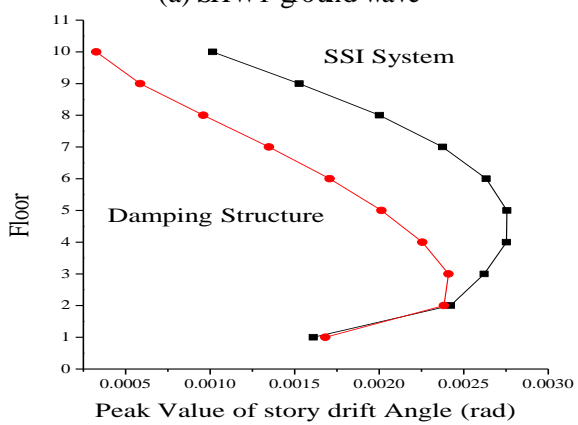

(b) SHW2 ground wave

Figure 7. Story drift angle peak curve of structure considering SSI effect

\section{Inter-story Shear Response Structure}

After observing the inter-story shear peak value of frame and its damping structure under rigid foundation, it is found 
that mild steel damper can obviously reduce inter-story shear force of structure while the extent of reduction indicated in the curve under SHW2 wave is obviously larger than that of SHW1 wave, especially on the bottom part of structure, thus it indicates that the type of wave has certain influence on damping effect.

It can be found in Figure 9 that the inter-story shear force of SSI structure without installing mild steel damper will increase before decreasing with the increase of floors under the effect of SHW2, which indicates the stiffness of structure is relatively small and weak story occurs under the effect of SHW2 wave. The shape of this curve, however, has changed after installing mild steel damper, and inter-story shear force of damping system decreases progressively from top to bottom, which indicates good damping effect of mild steel damper. Besides, mild steel damper has good effect on controlling inter-story shear peak value of structure; it has very obvious effect especially on controlling inter-story shear force of structure's upper floor.

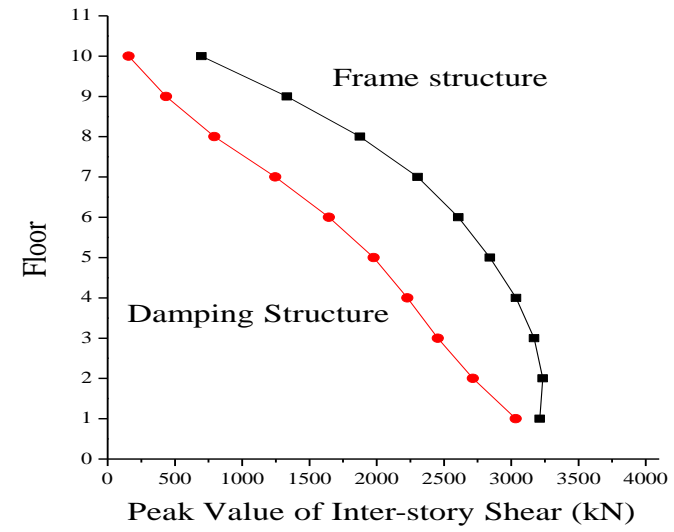

(a) SHW1 ground wave

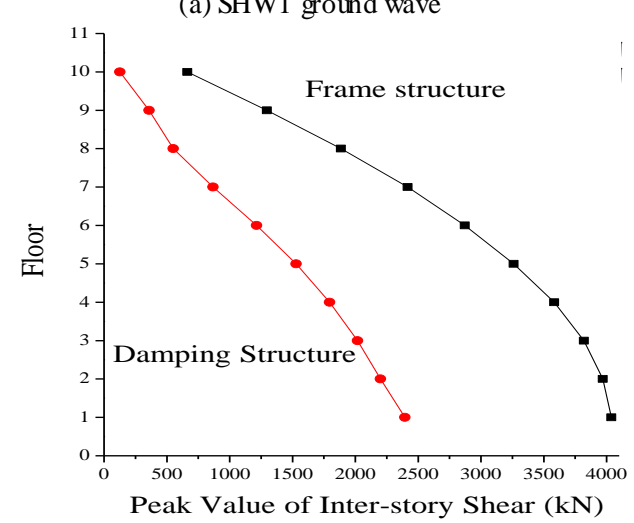

(b) SHW2 ground wave

Figure 8. Inter-story shear peak curve of structure under rigid foundation assumption

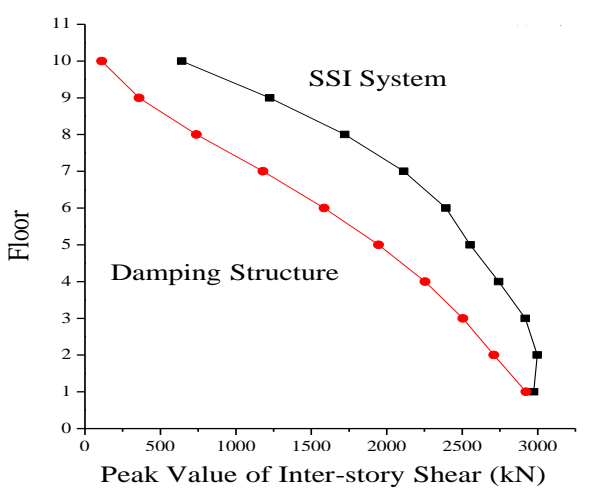

(a) SHW1 ground wave

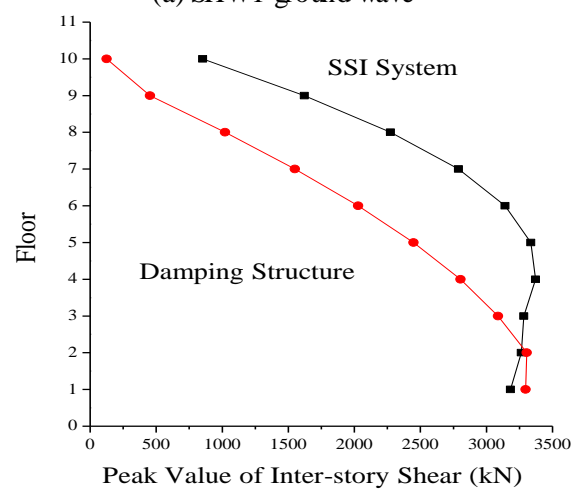

(b) SHW2 ground wave

Figure 9. Inter-story shear peak curve of struct ure considering SSI effect

\section{CONCLUSIONS}

The finite element models of structure with mild steel damper considering SSI were built up. Different parameters of viscous dampers, soils and forms of foundation have been conducted to study The influence of SSI effect on the damping effect of mild steel dampers was studied. From these studies, the following conclusions are obtained.

(1) Whether it is the frame structure under rigid foundation assumption or the frame structure considering SSI effect, mild steel damper installed in it will have good damping effect and can control structure's displacement response, inter-story shear force etc well. Mild steel damper, however, cannot stably control the base shear force of the structure because it increases the stiffness of the structure and also increases the damping of the structure.

(2) Without installing mild steel damper, various responses of frame structure considering SSI effect will decrease in different degree comparing to rigid foundation assumption. Thus, it can be concluded that SSI is useful to seismic performance of frame structure in some degree.

(3) After comparing average damping rates of frame structure, it can be found that average damping rates of various indexes of damping structure will decrease after considering SSI, which indicates that SSI will reduce the damping effect of the mild steel dampers on frame structure. In addition, the results under the two seismic waves indicate great difference in decrease extent of structure's average damping rate; therefore, difference in seismic wave's type 
will also influence the damping effect of the mild steel dampers.

(4) The design of the mild steel damper in damping structures under rigid foundation assumption will be unsafe in engineering application.

\section{ACKNOWLEDGMENT}

This project was supported as a project of the National Natural Science Foundation of China (Grant No. 51478355). The study was also supported by the Ministry of Science and Technology of China (Grant No. SLDRCE14-B-22).

\section{REFERENCES}

[1] Zheng Lu, Xiaoyi Chen, Dingchang Zhang and Kaoshan Dai. Experimental and analytical study on the performance of particle tuned mass dampers under seismic excitation [J]. Earthquake Engineering and Structural Dynamics. 2016. 11, DOI: 10.1002/eqe. 2826 .

[2] Zheng Lu, Dianchao Wang, Sami F. Masri and Xilin Lu. An experimental study of vibration control of wind-excited high-rise buildings using particle tuned mass dampers [J]. Smart Structures and Systems. 2016.7. 18(1):93-115.

[3] Cao Zhiyuan. Structure and Medium Interaction Theory and Its Application [M]. Nanjing: Hehai University Press, 1993.

[4] Wang Fengxia, Ou Jinping. SSI System Aseismic pushover Analysis method Based on Energy Spectrum Method [J]. Seismic Engineering and Engineering Vibration, 2006, 26 (5): 88-94.
[5] Du Dongshen, Liu Weiqing, Wang Shuguang, Li Weiwei, Li Changping. Analysis of SSI Effect's Impact on Seismic Isolation Structure's Seismic Response and Damage [J]. Seismic Civil Engineering Journal, 2012, 45 (5): 18-25.

[6] Zhang Wenyuan, Li Shuying, Li Dongwei. Simulation analysis on hysteret ic behavior and vibration suppression of the mild steel damper with the diamond-shaped opening and added damping and stiffness [J]. World seismic engineering, 2007, (1): 151-155.

[7] China Academy of Building Research (CABR). GB50011-2010 Code for Seismic Design of Buildings [S]. Beijing: China Construction Industry Press, 2010.

[8] Zhu Bofang. Theory and Application of Finite Element Method [M]. Beijing: China WaterPower Press, 1998.

[9] Zhang Kexu, Xie Junwen. Soil Dynamics [M]. Beijing: Seismological Press, 1989.

[10] Chen Guoxing, Zhuang Haiyang. Soil Dynamic Constitutive Relation and It s Parameter Research Basing on Davidenkov Skeleton Curve [J] Geotechnical Engineering Journal, 2005, 27 (8): 860-863.

[11] Li Peizhen. Vibration Table Testing and Computer Simulating Analysis of Structure - Dynamic Foundation Interaction System [D]. Shanghai: School of Architecture and Construction of Tongji University, 2002.

[12] Liu Jinbo, Du Yixin, Yan Qiushi. Realization of Viscoelastic Artificial Boundary and Seismic Input in General Finite Element Soft ware [M]. Journal of Disaster Prevention and Mitigation Engineering, 2007, 27 (supplement issue): $37-42$.

[13] Tongji University. DGJ08-9-2013 Shanghai Code of Aseismic Design of Buildings [S]. Shanghai. 